\title{
ABSENTEÍSMO E PRODUÇÃO DE DENDÊ NA AMAZÔNIA: TRABALHO E QUALIDADE DE VIDA EM TOMÉ-AÇU/PA
}

\author{
Rodrigo Fraga Garvão ${ }^{1}$ \\ Warleson Pontes Ribeiro ${ }^{2}$ \\ Robson Cristo Viana ${ }^{3}$ \\ Rayra Brandão ${ }^{4}$
}

\begin{abstract}
RESUMO
O presente artigo aborda o absenteísmo em relação à produção, apresentando como objetivo principal descrever o absenteísmo dentro do processo de produção de dendê de umaempresa agrícola do município de Tomé-Açu/PA, trazendo uma quantificação das taxas de absenteísmo, além de identificar e descrever as causa e consequências do absenteísmo dentro da organização. A metodologia empregada na pesquisa foi através de um estudo de caso de caráter quantitativo e qualitativo com a utilização de pesquisa documental e bibliográfica. Em seguida foi realizada uma coleta de dados através da aplicação de questionários e entrevista, e um levantamento de índices e taxas referentes ao absenteísmo nos anos de 2014 a 2018. O tratamento dos dados sucedeu-se através da análise dos dados fornecidos pela organização e realizou-se também a tabulação dos questionários aplicados em uma amostra de $20 \%$ dos colaboradores do setor de produção da empresa juntamente com o auxílio de uma entrevista com os gestores. Os resultados obtidos apresentam uma redução dos índices de absenteísmo através de políticas internas adotadas pela empresa, no entanto, vê-se a necessidade de atenção em relação à saúde dos trabalhadores. Assim, propõem-se ações e medidas que visam melhorar essas questões.
\end{abstract}

Palavras-Chaves: Absenteísmo. Processo de Produção. Dendê.

\section{ABSENTEEISM AND OIL PALM PRODUCTION IN THE AMAZON: WORK AND QUALITY OF LIFE IN TOMÉ-AÇU/PA}

\begin{abstract}
The present article addresses absenteeism in relation to production, presenting as main objective to describe absenteeism within the process of yielding palm oil from an agricultural company in the municipality of Tomé-Açu/PA, bringing a quantification of absenteeism rates, besides identifying and describing the causes and consequences of absenteeism within the organization. The methodology used in the research was through a quantitative and qualitative case study with the use of documentary and bibliographic research. Then, a data collection was performed through the application of questionnaires and interviews, and a survey of indexes and rates related to absenteeism in the years 2014 to 2018 . The data were processed through the analysis of the data provided by the organization and the tabulation of questionnaires applied in a sample of $20 \%$ of employees in the company's production sector was also tabulated, together with the help of an interview with managers. The results obtained present a reduction in absenteeism rates through internal policies adopted by the company, however, we see the need for attention in relation to workers' health. This proposes actions and measures aimed at improving these issues
\end{abstract}

Keywords: Absenteeism. Production Process. Palm oil.

\footnotetext{
${ }^{1}$ Doutorando em Agriculturas Familiar e Desenvolvimento sustentável (DAAFS/PPGAA/UFPA). Mestre em Desenvolvimento e meio ambiente urbano (Universidade da Amazônia). Professor da Universidade Federal Rural da Amazônia (UFRA). E-mail: rodrigofragabh@gmail.com

${ }^{2}$ MBA em Gestão de Pessoas pelo Centro de Ensino Superior Dom Alberto Ltda, CESDA_PPROV/BRASIL, Administrador pela Universidade Federal Rural da Amazônia.

${ }^{3}$ Administrador pela Universidade Federal Rural da Amazônia.

${ }^{4}$ Doutora em Engenharia Civil (PPGEC/UFPA), professora da Universidade Federal Rural da Amazônia (UFRA).
} 
Data de submissão: 21.04 .2021

Data de aprovação: 15.05 .2021

\section{INTRODUÇÃO}

O absenteísmo sempre foi uma questão difícil para as organizações controlarem. Essa ausência do empregado ao trabalho pode causar atrasos no processo produtivo, na realização das tarefas da empresa e podem causar sobrecarga de trabalho para alguns colaboradores. Com isso, consequências como a desmotivação, geração de conflitos e, até mesmo, a queda na produtividade podem ocorrer.

O absenteísmo na atualidade sai de seu contexto de ser tratado apenas como uma causa médica passando a ser encarado como um problema que atinge todos os níveis da organização, passando até para fora da empresa, atingindo a sociedade de várias maneiras. AOrganização Mundial do Trabalho (OMT) em uma coletânea de mais de 50 trabalhos com institutos renomados nas áreas de saúde ocupacional, identificou que o absenteísmo por doença alcança a $8^{\circ}$ causa mais usada para se ausentar do serviço (AFFONSO, 2014).

Para Santiago (2017), a saúde do trabalhador é umas das causas na qual se mais tem aumento da ausência do empregado ao serviço. As organizações que querem diminuir o seu índice de absenteísmo devem estar atentas à saúde mental e física de seu colaborador para, assim, montar um plano de ação visando à diminuição do índice e melhorar a qualidade de vida de seus funcionários.

Estudos feitos por Lee e Eriksen (1990) dizem que o absenteísmo é inversamente proporcional à satisfação dos colaboradores, isso pode acontecer como uma forma de fugir de situações indesejáveis no trabalho. A investigação dos elementos como condição de trabalho, cultura organizacional, estilo de supervisão e motivação da equipe de trabalho colaboram para a identificação das causas do absenteísmo. Saber lidar com essas particularidades pode ser uma das formas de administrar o absenteísmo na organização.

Vale ressaltar que o processo de produção para uma organização é primordial para alcançar seus objetivos e metas e, para que isso aconteça, é necessário ter funcionários motivados, comprometidos e física e mentalmente estabilizados, pois esses fatores são importantes para que a produção seja capaz de atingir suas expectativas.

A produção de óleo de palma no país vendo sendo estudada desde a década de 50, na qual o Institut de Recherches Pour Lês Huiler et Les Oleaginex (IRHO), após estudos realizados, identificou que a Amazônia era a região mais favorável para o cultivo da culturade dendê no Brasil, nesta região existiam grandes quantidade de terra e clima propício para o desenvolvimento da planta.

O mercado de palma de dendê está presente em dois principais segmentos: de alimentos e de combustível. No segmento de alimentos, a matéria-prima (óleo de palma), oriunda da extração da polpa do fruto e da semente do fruto de dendê, é um dos produtos maisconsumidos no mundo atualmente, estando presente em grande parte do ramo alimentício. Ofruto de dendê pode ser encontrado nas composições de fabricação de sorvete, manteigas, óleo para frituras, fabricação de pão, entre outros produtos para o setor de alimentos.

No mercado de Biocombustível, o óleo de palma de dendê tem um grande potencial produtivo para a produção do produto, pois, comparado a outras oleaginosas como, por exemplo, a soja, o dendê tem um elevado balanço enérgico para a fabricação do combustível no qual o fruto pode chegar em até $6.000 \mathrm{~kg} / \mathrm{ha}$ quando atinge o ápice de produtividade, diferente da soja que pode chegar em até $550 \mathrm{~kg} / \mathrm{ha}$ em seu ápice (EMPRAPA, 2012).

O grande entrave para a produção de biocombustível no país com o uso de óleo de palma é seu alto custo com mão de obra, em que grande parte do cultivo é feito de forma manual e 
também a produção ainda não é autossuficiente para atender o mercado interno. Assim, fazendo com que o país importe o insumo para que o biocombustível seja produzido. Para que a produção de óleo de palma se torne mais viável para produção de biocombustível,vêm sendo feitos grandes investimentos na área de tecnologia do cultivo de dendê tonando, assim, as atividades ligadas à colheita do fruto mais mecanizadas para, deste modo, diminuir o uso de mão de obra manual nas plantações de dendê.

Segundo a Associação Brasileira de Produtores de Óleo de Palma (ABRAPALMA), o Brasil irá se tornar autossuficiente no consumo de óleo de palma a partir de 2019 alcançando, assim, a produção de mais de 500 milhões de toneladas de óleo de palma produzidas por ano. Esta notícia para o mercado brasileiro é bastante favorável tendo em vista que a partir de 2020 a China, grande parceira comercial do Brasil passará a usar $10 \%$ de etanol misturado à gasolina. Um estudo realizado pela ABRAPALMA prevê que em 2023 45\% das fontes de energia do país serão de fontes renováveis, principalmente com o uso de biocombustível (ABRAPALMA, 2018).

Diante disso, o mercado de óleo de palma tem muito a crescer ao decorrer dos anos devido às novas tecnologias e investimentos que serão inseridos na produção deste cultivo.

Assim, a presente pesquisa foi realizada como um estudo de caso em uma empresa do ramo agrícola produtora de dendê do município de Tomé-Açu/PA, onde pretende-se identificar as principais causas do absenteísmo no processo de produção da organização entre os anos de 2014 a 2018, abordar como esta ausência do colaborador pode interferir na produtividade e, posteriormente, propor melhorias para a administração da produção e para agestão de pessoas no que tange os níveis de absenteísmo.

\section{1 ÍNDICES DE ABSENTEÍSMO (PERÍODO DE 2014 A 2018)}

Neste momento do artigo, serão apresentados os dados que foram analisados e que nos trouxeram as principais causas do absenteísmo dentro da organização. Ressalta-se que a pesquisa abrangeu aproximadamente 439 colaboradores do setor de produção da empresa. A tabela 1 identifica o total de absenteísmo entre 2014 a 2018.

Tabela 1: Absenteísmo entre 2014 a 2018.

\begin{tabular}{lc}
\hline Ano & Absenteísmo Geral \\
\hline 2014 & $3,87 \%$ \\
2015 & $6,14 \%$ \\
2016 & $2,41 \%$ \\
2017 & $1,28 \%$ \\
2018 & $1,10 \%$
\end{tabular}

Fonte: Ribeiro e Viana (2019)

Conforme apresentado na tabela anterior, os índices de absenteísmo dos anos de 2014a 2018, levando em consideração o índice de absenteísmo sugerido pela Organização Mundial da Saúde (OMS) de 1,4\%. A partir disso observa-se que nos três primeiros anos a organização teve elevados índices de absenteísmo e nos dois últimos anos estudados esses índices tiveram uma redução considerável.

Para uma melhor compreensão do absenteísmo dentro da organização, elaborou-se um detalhamento do absenteísmo geral subdividindo os dados em absenteísmo voluntário,médico e abonado, como observado nas tabelas 2,3 e 4 . 
Segundo Borchardt (2018), o absenteísmo médico se refere às faltas dos colaboradores por motivos de enfermidade. Sendo assim, observando os cinco anos estudados (2014 a 2018) na tabela 2, o absenteísmo médico, o qual é relativo apenas às faltas justificadas com atestados médicos, apresenta o índice acima da média apenas no ano de 2015, com um percentual de $2,19 \%$, nos demais, os índices estão dentro do sugerido pela OMS.

Tabela 2: Índice de Absenteísmo Médico de 2014 a 2018.

\begin{tabular}{cc}
\hline Ano & Absenteísmo Médico \\
\hline 2014 & $1,04 \%$ \\
2015 & $2,19 \%$ \\
2016 & $0,71 \%$ \\
2017 & $0,81 \%$ \\
2018 & $0,40 \%$ \\
\hline
\end{tabular}

Fonte: Ribeiro e Viana (2019)

No que se refere aos índices de absenteísmo voluntário, ou seja, às faltas injustificadas dos colaboradores por motivos particulares, sem justificativa médica ou amparo legal (AFFONSO, 2014), constatou-se também uma redução no decorrer dos anos analisados. Essa redução acontece a partir do ano de 2016, onde a convenção coletiva de trabalho trouxe, emsua cláusula nona, a permissão para empresa efetuar a suspensão do vale-alimentação do colaborador no mês em que ele tivesse faltas não justificadas. Essa medida trouxe uma redução de aproximadamente $60,34 \%$ na quantidade de faltas dentro da organização se compararmos com o ano de 2015, conforme observado na tabela 3.

Tabela 3: Índice de Absenteísmo Voluntário de 2014 a 2018.

\begin{tabular}{cc}
\hline Ano & Absenteísmo Voluntário \\
\hline 2014 & $2,83 \%$ \\
2015 & $3,48 \%$ \\
2016 & $1,38 \%$ \\
2017 & $0,26 \%$ \\
2018 & $0,51 \%$ \\
\hline
\end{tabular}

Fonte: Ribeiro e Viana (2019)

No ano de 2017 a empresa adotou algumas medidas para que houvesse redução no absenteísmo. A partir disso, foi implantado na organização o sistema de escala 4x4, ou seja, para cada 04 dias trabalhados o colaborador tem o direito a 04 dias de folga. Com isso foi possível perceber uma redução considerável no número de faltas dos colaboradores. Assim pode-se dizer então que o total da redução do índice de absenteísmo dos colaboradores da produção foi de $92,53 \%$ se compararmos como 2015, ano este em que a organização apresentou o maior índice de absenteísmo.

Como observado na tabela 4, o absenteísmo abonado o qual é relativo às faltas injustificadas, porém abonadas pelo gestor, observa-se que no ano de 2014 a organização não teve colaboradores com faltas abonadas pelo fato da empresa não adotar o abono de faltas injustificadas. A partir de 2015, a organização passou a abonar faltas injustificadas em alguns 
casos, o que ocasionou uma redução no decorrer do período analisado. Essa redução se dá pelos mesmos motivos da redução do absenteísmo voluntário, ou seja, através das novas cláusulas da convenção coletiva de trabalho e pela adoção da escala $4 \times 4$ já mencionada anteriormente, sendo assim, em alguns casos não há necessidade de liberar o trabalhador pararesolver questões pessoais, uma vez que a nova escala lhe concede 4 (quatro) dias de folga na semana.

Tabela 4: Índice de Absenteísmo Abonado de 2014 a 2018.

\begin{tabular}{cc}
\hline Ano & Absenteísmo Abonado \\
\hline 2014 & - \\
2015 & $0,47 \%$ \\
2016 & $0,33 \%$ \\
2017 & $0,21 \%$ \\
2018 & $0,18 \%$ \\
\hline
\end{tabular}

Fonte: Ribeiro e Viana (2019)

Se compararmos os índices de absenteísmo nos anos estudados, pela observação do Gráfico 1, constata-se que ao longo dos anos houve reduções consideráveis nos níveis dos índices de absenteísmo dentro da organização, em decorrência das medidas adotadas pela empresa.

Gráfico 1: Índices de Absenteísmo Voluntário, Médico e Abonado

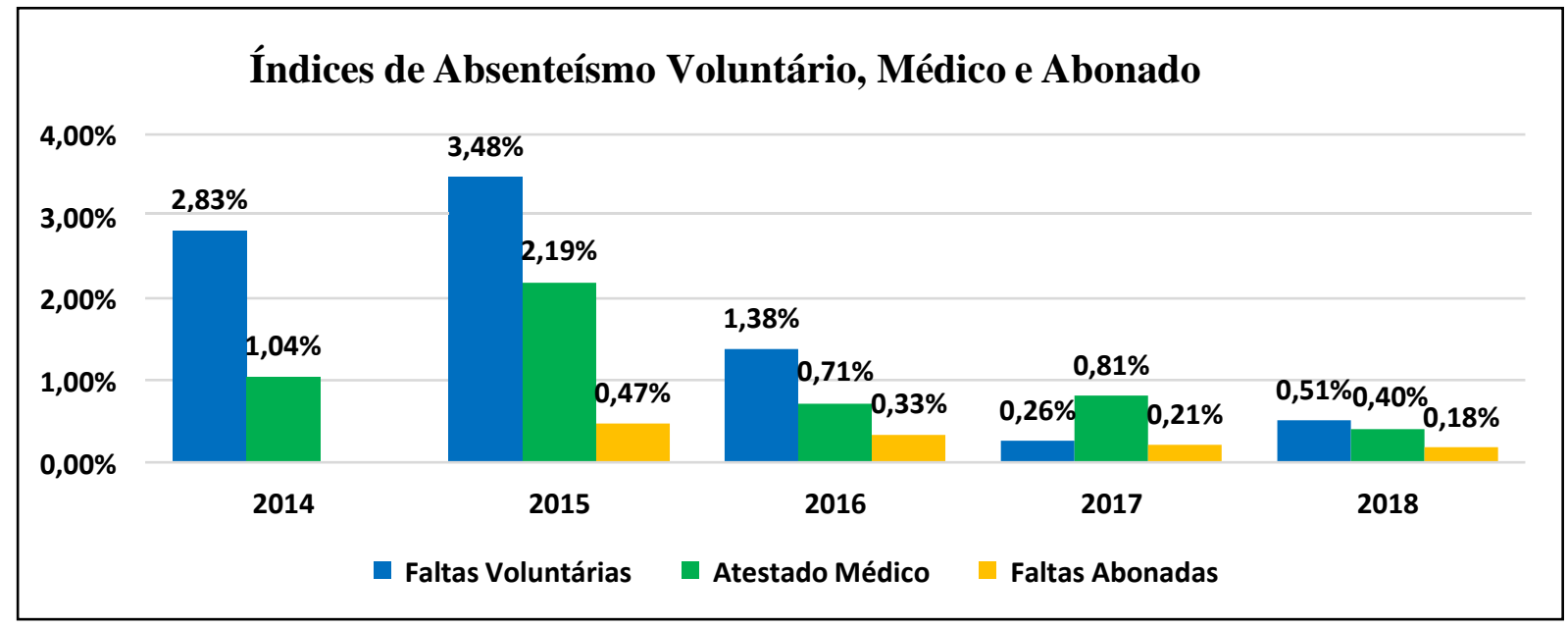

Fonte: Ribeiro e Viana (2019).

No ano de 2016, o $\$ 1^{\circ}$ da Cláusula Nona do Acordo Coletivo de Trabalho (ACT) da empresa previa o desconto do vale-alimentação caso o trabalhador se ausentasse. Assim, com uma falta descontava-se do colaborador $30 \%$ do benefício; com duas faltas, o desconto era equivalente a $50 \%$ e a partir de três faltas descontava-se $100 \%$ do vale- alimentação. No ano de 2017 as porcentagens de descontos foram fixadas em 40\%, 60\% e 100\% respectivamente de acordo com o $\S 1^{\circ}$ da Cláusula Nona do ACT do referido ano.

A partir do ano de 2018, a cláusula décima quinta do ACT do referido ano trouxe a implantação da escala $4 \times 4$ para os trabalhadores da produção, ou seja, quatro dias de trabalho com jornada de 12 horas cada e quatro dias de descanso. E, no que se refere ao vale-alimentação, foram alteradas as políticas de descontos, assim, o colaborador que tiver uma falta, desconta-se o equivalente a $50 \%$ do seu benefício e a partir de duas faltas desconta-se $100 \%$ do valor do vale- 
alimentação conforme o Parágrafo Único da Cláusula Nova do ACT.

Em entrevista realizada com um dos supervisores da organização, observou-se que além das medidas previstas na convenção coletiva de trabalho, o supervisor tem determinada autonomia para aplicar advertências escritas e aplicar restrições aos funcionários que possuem excesso de faltas, conforme a fala do entrevistado que diz

\begin{abstract}
o trabalhador quando ele tem mais de três a quatro faltas eu aplico, pelo menos, uma advertência por escrito nele tá mais ou menos isso daí ou eu interrompo o trabalhador a fazer hora extra porque quando a gente tá com umademanda alta de fruto, né, então a gente precisa de trabalhadores para vir na extra $100 \%$. Então é uma bonificação para os melhores trabalhadores, digamos assim, esse trabalhador que tem falta, ele já não vem para o 100\%. Uma maneira punir. (entrevistado, sic)
\end{abstract}

Essas medidas corroboraram para uma redução significativa no índice de absenteísmo da organização, assim, até o último ano estudado evidenciando-se que a empresa está com índice de absenteísmo dentro do nível considerado aceitável no Brasil, conforme a $\mathrm{OMS}^{5}$.

\title{
2 RELAÇÃO DO ABSENTEÍSMO COM A PRODUÇÃO
}

Com base nessas informações, pode-se fazer uma análise detalhada entre os índices de absenteísmo e a produção da empresa dentro dos anos estudados, conforme observa-se no gráfico 2.

Gráfico 2: Relação do Absenteísmo com a Produção entre 2014 e 2018

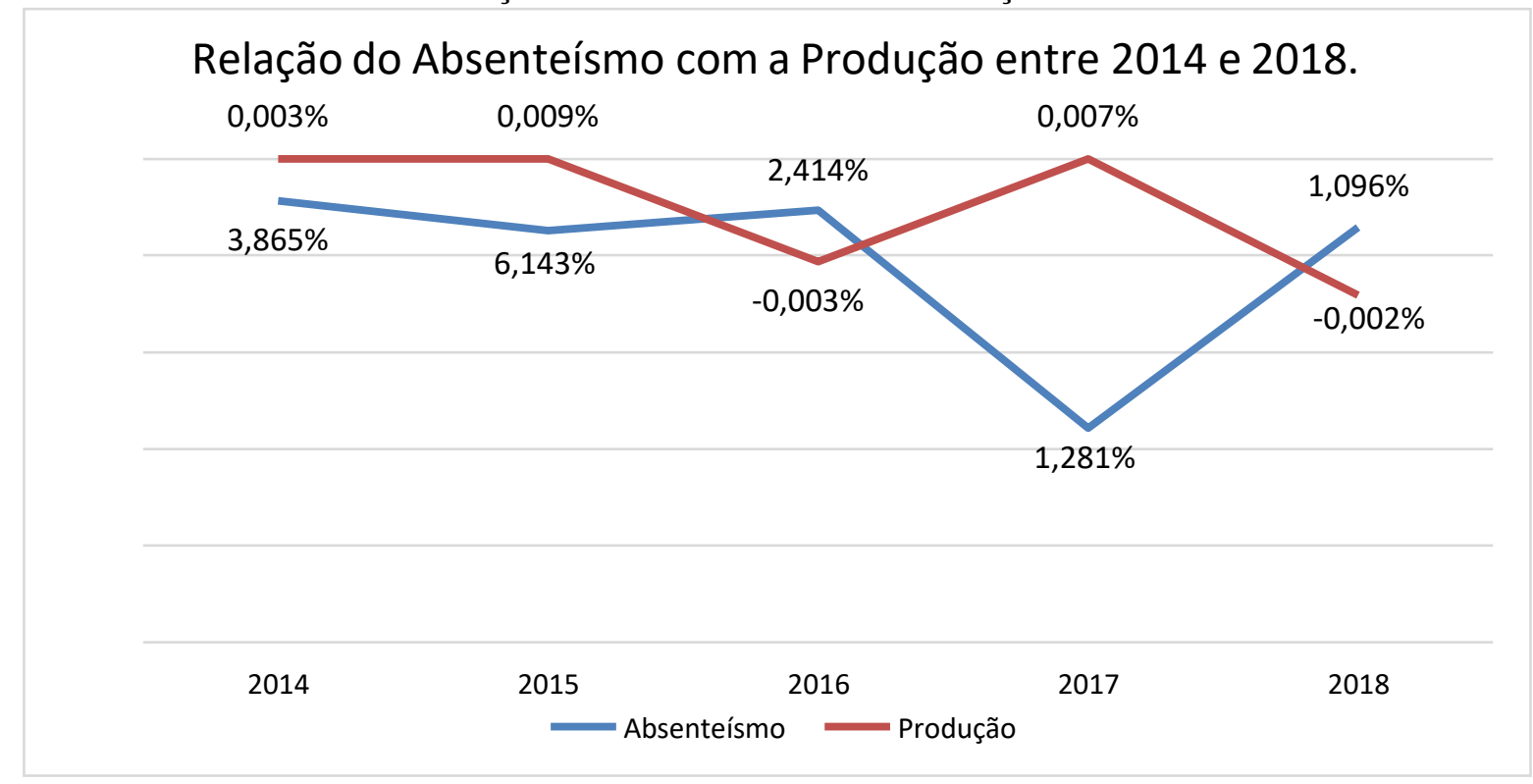

Fonte: Ribeiro e Viana (2019)

\footnotetext{
${ }^{5}$ A Organização Pan-Americana da Saúde (OPAS) trabalha com os países das Américas para melhorar a saúde e a qualidade de vida de suas populações. Fundada em 1902, é a organização internacional de saúde pública mais antiga do mundo. Atua como escritório regional da Organização Mundial da Saúde (OMS) para as Américas e é a agência especializada em saúde do sistema interamericano. O organismo internacional oferece cooperação técnica em saúde a seus países membros; combate doenças transmissíveis e doenças crônicas não transmissíveis, bem como suas causas; e fortalece os sistemas de saúde e de resposta ante emergências e desastres.(https://www.paho.org/pt/brasil).
} 
Através dos dados analisados ao longo dos anos, nota-se que mesmo com os elevados índices de absenteísmo nos primeiros anos (2014 e 2015) a variação da produção na empresaem estudo foi irrisório, ou seja, os trabalhadores conseguiram atingir a meta estipulada mesmo com redução decorrente das faltas de alguns funcionários ao longo do período. E nosanos seguintes onde houve a redução do absenteísmo a produção também se manteve dentrodo estipulado, com exceção do ano de 2016 e 2018, onde a produção não foi atingida, faltando apenas $0,003 \%$ e $0,002 \%$ respectivamente em sua projeção, assim essa variação pode serconsiderada como insignificante para a organização.

\section{PRINCIPAIS FATORES DE AUSÊNCIA DO COLABORADOR AO SERVIÇO}

Após o levantamento dos índices de absenteísmo do setor de produção da organização, foi possível identificar quais os principais fatores que têm contribuído para os níveis de absenteísmo. Assim, conforme observa-se na Tabela 5, o principal fator das ausências dos empregados dentro da organização em estudo, está ligado aos fatores pessoais conforme descreve Vieira (2016), ou seja, do total geral de absenteísmo do setor deprodução, 41,67\% são relacionados a atestados médicos.

Santiago (2017), retrata que a saúde do trabalhador é umas das causas que mais tem relação com as ausências do colaborador ao serviço e conforme a OMS esse fator está em $8^{\circ}$ lugar como a causa mais usada para justificar as ausências.

Tabela 5: Ausência por Fatores Pessoais.

\begin{tabular}{lc}
\hline \multicolumn{1}{c}{ Descrição } & Quantidade \\
\hline Atestado Médico & $41,67 \%$ \\
Acompanhamento de Filho & $14,58 \%$ \\
Falecimento de Familiar & $12,50 \%$ \\
Nascimento de Filho & $8,33 \%$ \\
Comparecimento em Juízo & $4,17 \%$ \\
Acompanhamento de Gravidez & $4,17 \%$ \\
Realização de Prova & $4,17 \%$ \\
Doação de Sangue & $2,08 \%$ \\
Casamento & $2,08 \%$ \\
Acidente de Trânsito & $2,08 \%$ \\
Alistamento Militar & $2,08 \%$ \\
Alcoolismo & $2,08 \%$ \\
\hline
\end{tabular}

Fonte: Ribeiro e Viana (2019)

Isto posto, evidenciou-se através da aplicação do questionário que os dois principais motivos dos atestados médicos estão relacionados a dores na coluna e dores nas costas, como percentual $29,63 \%$ e $14,81 \%$ respectivamente. Em seguida as dores nas coxas e dor no peitose igualam com $11,11 \%$ cada um, conforme apresentado no gráfico 3. 
Gráfico 3: Principais Dores Apresentadas Nos Atestados Médicos

\section{Principais Dores Apresentadas Nos Atestados Médicos}

\section{$29,63 \%$}

$14,81 \%$

$11,11 \% 11,11 \%$
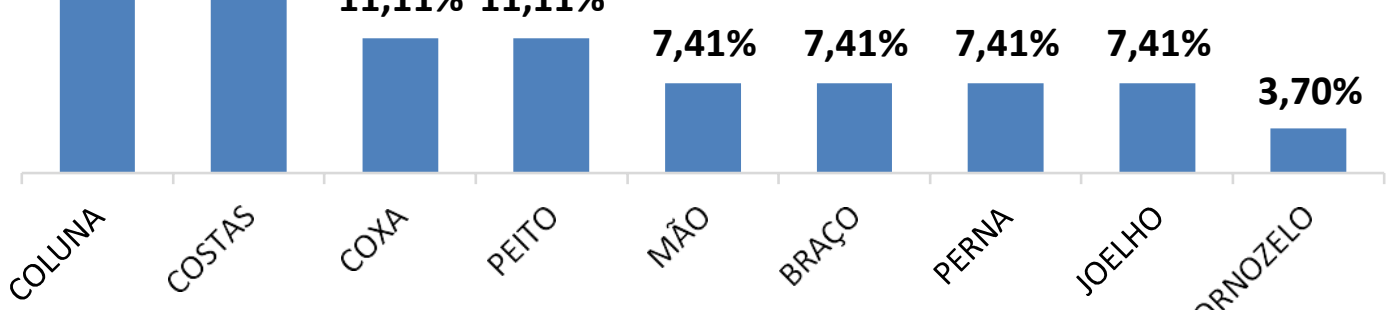

Fonte: Ribeiro e Viana (2019)

Com base nos estudos realizados na organização, destaca-se a falta do cumprimento da ginástica laboral, essa, por sua vez pode ser entendida como a execução de exercícios de aquecimento musculoesquelético, que tem por objetivo o preparo do organismo para o trabalho físico (DELBIN \& MORAES, 2005).

Assim, evidenciou-se que apenas 4,65\% dos trabalhadores que participaram da pesquisa realizam a ginástica laboral frequentemente e que $51,16 \%$ só realizam os exercíciosæ̀ vezes e 44,19\% nunca realizaram nenhum tipo de exercício voltado à ginástica laboral.

Gráfico 4: Prática de Ginástica Laboral

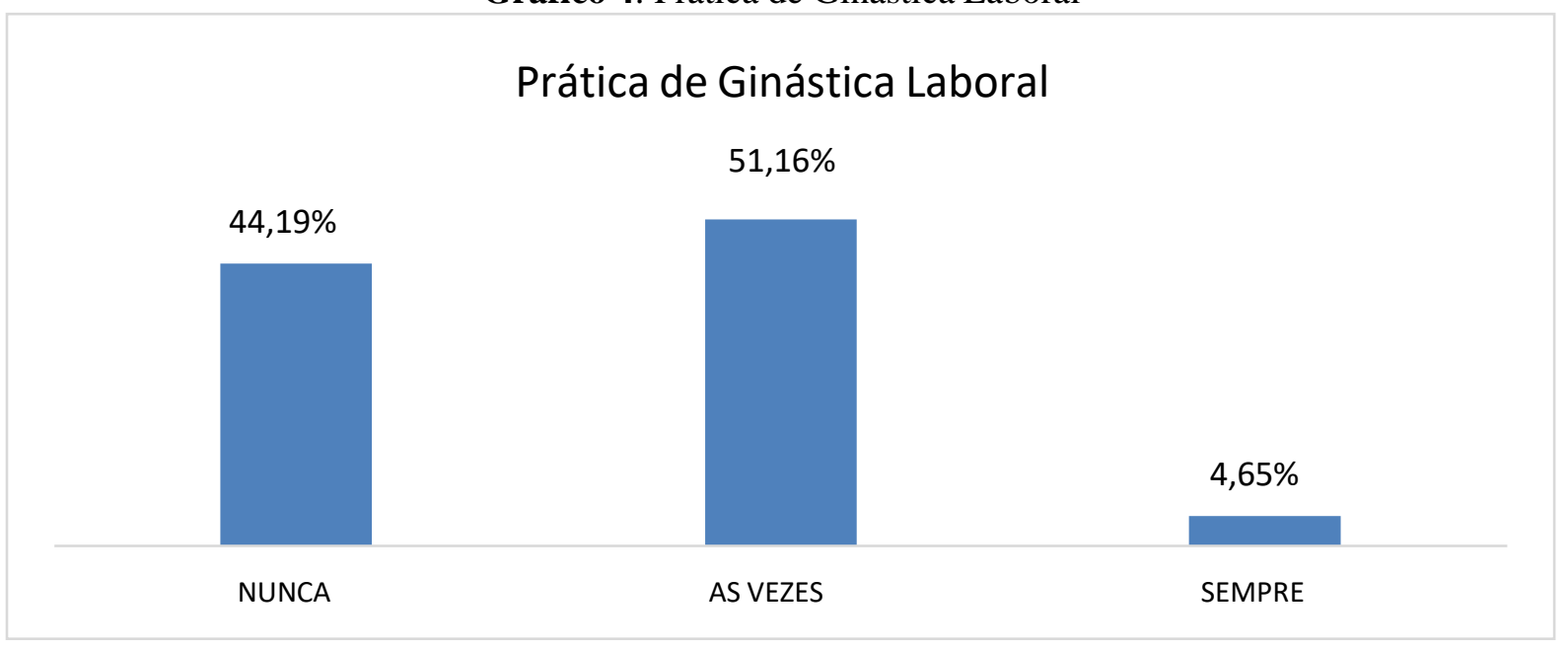

Fonte: Ribeiro e Viana (2019)

Como consequência, observa-se que a falta dos exercícios ligados à ginástica laboral, corrobora para os altos índices de atestados médicos relacionados a dores na coluna e dores nas costas, devido à atividade exercida pelos trabalhadores rurais exigir um esforço do trabalhador que pode sobrecarregar seus membros superiores e regiões do tronco do corpo.

Sendo assim, a GL tem por finalidade trazer mudanças na qualidade de vida dos colaboradores. Pois a atividade é praticada de maneira criativa e descontraída. O mais relevante na GL é a prevenção de doenças relacionadas ao trabalho repetitivo que geram dores 
musculares, estresse e dificulta a vida do trabalhador (MENDES \& LEITE, 2012).

No que tange os fatores ambientais relacionados ao absenteísmo, observa-se na Tabela 6, que a empresa possui apenas uma variável que influencia no absenteísmo, essa variável tem relação com o transporte dos colaboradores até o local de trabalho representando 47,62 \% dos motivos das ausências.

Tabela 6: Ausência por Fatores Ambientais

\begin{tabular}{cc}
\hline Descrição & Motivo Ambiental \\
\hline Transporte até a Empresa & $47,62 \%$ \\
\hline
\end{tabular}

Fonte: Ribeiro e Viana (2019)

Dentro dos fatores organizacionais nota-se, na tabela 7 , que $23,81 \%$ das ausências estão ligadas às variáveis remuneração e condições de trabalho, demonstrando assim uma leve insatisfação dos colaboradores e 4,76\% está relacionado à qualidade da liderança do setor, ou seja, a forma como é efetuada a gestão dos colaboradores dentro da organização.

Tabela 7: Ausência por Fatores Organizacionais

\begin{tabular}{cc}
\hline Descrição & Motivo Organizacional \\
\hline Remuneração & $23,81 \%$ \\
Condição de Trabalho & $23,81 \%$ \\
Qualidade da Liderança & $4,76 \%$ \\
\hline
\end{tabular}

Fonte: Ribeiro e Viana (2019)

Com base nos resultados obtidos, constatou-se que apesar dos elevados índices de absenteísmo em alguns anos, a produção não foi afetada de maneira significativa. Por outro lado, aponta-se para um alto nível de absenteísmo dentro da organização devido aos atestados médicos por motivos de dores nas costas e na coluna que, por sua vez, estão relacionados à falta da ginástica laboral por parte dos colaboradores.

\section{CONSIDERAÇÕES FINAIS}

Ao analisar os índices de absenteísmo dentre os anos estudados foi possível constatar uma redução considerável no decorrer dos anos de 2014 a 2018, contudo, evidenciando queo índice mais elevado foi de 6,14\% no ano de 2015 e, através de alguns métodos adotados pela organização, observou-se que a redução obtida pela empresa contribuiu para que a mesma obtivesse o nível aceitável de absenteísmo recomendado pela OMS no Brasil, ou seja,foi possível comprovar que a partir ano de 2017 a empresa obteve o índice de 1,28\% e o menor índice se deu no ano de 2018 com apenas $1,10 \%$.

Para um melhor entendimento dos dados obtidos, elaborou-se um detalhamento dos tipos de absenteísmo abordados na pesquisa, sendo eles, absenteísmo voluntario, médico e abonado. Assim constatou-se que o absenteísmo voluntário apresentou os maiores índices nos três primeiros anos pesquisados (2014 a 2016). Por outro lado, o absenteísmo médico cresceu do ano de 2014 para 2015, e no ano de 2016 houve uma redução de 67,58\% no nível de absenteísmo médico e nos anos de 2017 e 2018 houve apenas pequenas variações desse índice. Enquanto isso, o absenteísmo abonado, o qual possui um índice baixo, também reduziudevido às normas e medidas adotadas pela organização. 
No que tange os índices de absenteísmo em relação à produção, apesar dos elevados índices em alguns anos, constatou-se que não houve alterações relevantes na produção, ou seja, apesar da grande quantidade de faltas, os colaboradores alcançaram as metas estabelecidas para a produção. Por outro lado, vale ressaltar a importância de uma gestão eficiente das políticas de qualidade de vida dos colaboradores da organização, uma vez que os mesmos podem ter uma sobrecarga de trabalho para poder compensar o colaborador que faltou e assim conseguir que a produção seja atingida.

Entretanto, tratando-se dos fatores relacionados ao absenteísmo, através da análise dos dados foi possível constatar que dentre os principais fatores pessoais $41,67 \%$ são referentes a atestados médicos e entre os motivos dos atestados, as principais causas são doresna coluna e nas costas, com $29,63 \%$ e $14,81 \%$ respectivamente dos casos. Essas dores se dão pelo fato que a atividade exercida pelos trabalhadores rurais, exige um elevado esforço físico e movimentos repetitivos nas regiões lombar e costal.

Outro motivo que corrobora para esse índice de atestados médicos, é o fato que 44,19\% dos colaboradores nunca praticam a ginástica laboral (GL) antes da realização das atividades e $51,16 \%$ realizam a GL às vezes, ou seja, somente $4,65 \%$ dos colaboradores estãopraticando frequentemente a GL antes das atividades que irão exercer.

Isto posto, conforme já mencionado em relação à organização em estudo os elevados índices de absenteísmo não afetou de forma significativa a produção, porém, observa-se uma deficiência quando trata-se sobre a saúde dos colaboradores, ou seja, o prejuízo da empresa não está ocorrendo na produção, mas sim no capital humano, tendo em vista que o absenteísmo gera uma sobrecarga nos trabalhadores presentes para que a meta seja alcançada e, como consequência, posteriormente esse trabalhador estará com a saúde prejudicada, sendo necessário o seu afastamento para tratamento, gerando assim um aumento no absenteísmo médico.

No que tange ao quadro de profissionais do SESTR, a empresa possui apenas 1 Engenheiro de Segurança do Trabalho, 1 Técnico de Segurança do Trabalho, 1 Enfermeiro do Trabalho e 1 Auxiliar de Enfermagem. Porém, mesmo que a organização tenha o quadro de profissionais conforme define a NR 31, ainda assim não seria sanado o problema de maneira total, tendo em vista que a distância entre os setores da organização exige uma logística complexa, assim dificultando a inspeção de segurança do trabalho.

Diante disso, recomenda-se a implementação de melhorias nas políticas de qualidadede vida dos trabalhadores, assim, podendo tornar obrigatória a prática da ginástica laboral antes da realização das atividades, podendo ser entre uma ou duas vezes por semana, tendo em vista que a GL traz benefícios para a saúde do colaborador e, consequentemente, pode reduzir os absenteísmos médicos relacionados às dores musculares e nas articulações. Recomenda-se também que a organização adote o quadro de profissionais de SESTR conforme a NR 31, onde será necessária a contratação de 1 Médico do Trabalho e um Técnicode Segurança do Trabalho. E no que tange a inspeção de segurança, atualmente os técnicos de segurança do trabalho se deslocam de carro entre os setores, onde é disponibilizado apenasum carro para os dois técnicos existentes, ou seja, sempre que um estiver efetuando a inspeção o outro terá que aguardar o retorno do mesmo para que posteriormente realize seu serviço. Assim, recomenda-se que o deslocamento dos técnicos entre os setores seja feito de motocicleta, podendo os dois técnicos se deslocarem cada um em um veículo (motocicleta) ao mesmo tempo para diferentes setores e realizem a inspeção de forma correta.

Dessa forma, considera-se que a pesquisa traz colaborações importantes a respeito do absenteísmo dentro da organização que, no entanto, podem ser aprofundadas em estudos futuros. Com os resultados obtidos pela pesquisa, tem-se a finalidade de contribuir para uma efetiva gestão do absenteísmo na organização. Esses resultados poderão contribuir para embasamentos nas ações dos gestores da empresa e para a elaboração de estudos futuros sobre 
absenteísmo.

\section{REFERÊNCIAS}

ABSENTEÍSMO. In: Dicionário Online de Português. Disponível em: https://www.dicio.com.br/absenteismo/. Acesso em: 25 de ago. de 2019.

AFFONSO, Sergio Luiz. Absenteísmo: Um Problema Complexo nas Organizações. 2014. Dissertação (Trabalho de conclusão de curso de Mestrado em Administração) - Faculdade de Ciências Empresariais da Universidade Fumec, 2014.

AGUIAR, Gizele de Almeida Souza; OLIVEIRA, Janine Rodrigues de. Absenteísmo: suas principais causas e consequências em uma empresa do ramo de saúde. Revista de Ciências Gerenciais, v. 13, n. 18, 2010.

ALMEIDA, Mônica de Oliveira. Estudo comparativo dos índices e causas do absenteísmono trabalho de diferentes grupos em uma organização hospitalar privada. Orientadora:Maria Fatima Bruno Faria. 2008. Monografia ( Especialista em Gestão de pessoas). Faculdade de Economia, Administração, Contabilidade e Ciências da Informação e Documentação, Universidade de Brasília, Brasília, 2008.

ASSOCIAÇÃO BRASILEIRA DE PROTUDORES DE ÓLEO DE PALMA. A Palma no BATISTA, Aline Aparecida Gava. Absenteísmo: fatores determinantes e consequências. Trabalho de Conclusão de Curso (Bacharel em Administração) - Instituto Municipal de Ensino Superior de Assis, Assis, 2012.

BORCHARDT, Géssica Mayra. Absenteísmo no ramo frigorífico: um estudo de caso no frigorífico Globoaves no município de Espigão do Oeste-RO. Trabalho de Conclusão de Curso (Bacharel em Ciências Contábeis) - Universidade Federal de Rondônia, Rondônia, 2018.

BRASIL E NO MUNDO. Abrapalma. Associação Brasileira de produtores de Óleo de Palma. Disponível em: http://www.abrapalma.org/pt/sobre-o-fruto-de-palma/. Acesso em: 28 de julh. de 2019.

BRASIL. Consolidação das Leis do Trabalho. Decreto-Lei no 5.442, de 01.mai.1943. Disponível em: http://www.planalto.gov.br/ccivil_03/decreto-lei/del5452.htm. Acesso em: 19. maio. 2019.

BRASIL. Ministério da Previdência Social. Anuário estatístico de acidentes de trabalho, 2017. Disponível em: http://sa.previdencia.gov.br/site/2018/09/AEAT-2017.pdf. Acesso em:19 maio. 2019.

BRASIL. Tribunal Superior do Trabalho. Súmula no32: Abandono de emprego (nova redação) - Res. 121/2003, DJ 19, 20 e 21.11.2003. Disponível em:

http://www.trtsp.jus.br/geral/tribunal2/TST/Sumulas.htm\#32. Acesso em: 19 maio. 2019

CHIAVENATO, Idalberto. Gestão de pessoas: e o novo papel dos recursos humanos nas organizações. 4. ed. Rio de Janeiro: Elsevier, 2014. 512 p. 
CHIAVENATO, Idalberto. Recursos humanos. 10. ed. São Paulo: Atlas, 2015. 544 p.

DELBIN, M. A.; MORAES, C. Por que implantar um programa de ginástica laboral na empresa? Revista de Administração, Espírito Santo do Pinhal, v. 5, n. 9, p. 7-9, 2005.

DUTRA, Joel Souza. Gestão de pessoas: modelo, processos, tendências e perspectivas. 2. ed. São Paulo: Atlas, 2016.

LEE, Jane B.; ERIKSEN, Lillian R. The effects of a policy change on three types of absence. The Journal of nursing administration, v. 20, n. 7-8, p. 37-40, 1990.

MARTINS, Petrônio G.; LAUGENI, Fernando P. Administração da Produção. 3. ed. São Paulo: Saraiva, 2015. 584 p.

MARTINS, R. A. Sistemas de medição de desempenho: um modelo para estruturação do uso. 1999. Tese (Doutorado em Engenharia) - Escola Politécnica da Universidade de São Paulo, São Paulo, 1999.

MENDES, Ricardo Alves; LEITE. Neiva. Ginástica Laboral, princípios e aplicações práticas. 3. ed. São Paulo: Manole, 2012. 256 p.

MILKOVICH, George T; BOUDREAU, John W. Administração de recursos humanos, 1. ed., reimpressão. São Paulo: Atlas, 2015. p.

MOREIRA, Daniel Augusto. Administração da Produção e Operações. São Paulo: Saraiva, 2017. $165 \mathrm{p}$.

TUBINO, Dalvio Ferrari. Manual de Planejamento e Controle da Produção. 3. ed. São Paulo: Atlas, 2017. 304 p.

VIEIRA, M. R. F. S. P. Satisfação No Trabalho e Absentismo dos enfermeiros de um Aces. Dissertação (Mestrado em direção e chefia dos serviços em enfermagem) - Escola Superior de Enfermagem do Porto. Porto, 2016. 